\title{
(De)Gendering Older Patients: Exploring Views on Aging and Older Patients in Romanian General Practitioners
}

\author{
(In)visbilización del género: Explorando perspectivas sobre \\ envejecimiento y pacientes mayores en médicos generales rumanos
}

\author{
Catrinel Craciun ${ }^{1}$ \\ Babes Bolyai University, Romania \\ Freie Universität Berlin, Germany
}

\begin{abstract}
Purpose: Demographic changes make it necessary to improve communication with older patients and design gender sensitive health promotion. The present article aimed to explore how general practitioners see old age and what role gender may play in their representations of aging. It also looked whether the gender of the older patients played a role for how general practitioners treated them. Methods: Episodic interviews were conducted with 17 women and 17 men who worked as general practitioners in Romania. Thematic coding was used to analyze data. Results: Findings showed that general practitioners saw old age as negative no matter their gender. Older patients were perceived as difficult and mostly older women were given as negative examples to illustrate treatment non-adherence and psychological or social problems related to aging. Conclusion: Negative aging views combined with a (de)gendering of aging patients may lead to maintain negative aging stereotypes and gender inequality in old age. Implications for preventing this from happening are discussed.
\end{abstract}

Keywords. Aging views, active aging, general practitioners, gender, older patients.

Resumen. Propósito: Los cambios demográficos hacen necesario mejorar la comunicación con pacientes mayores y diseñar promoción de la salud sensible al género. El presente artículo explora cómo médicos generales perciben la adultez mayor y qué rol puede jugar el género en sus representaciones sobre el envejecimiento. También examina si el género de los pacientes mayores jugó un rol en la forma en la que los médicos generales los trataron. Métodos: Se llevaron a cabo entrevistas episódicas con 17 mujeres y 17 hombres que trabajaron como médicos generales en Rumanía. Se usó codificación temática para analizar los datos. Resultados: Los hallazgos mostraron que los médicos generales ven la adultez mayor como negativa sin importar el género. Se percibió a los pacientes mayores como difíciles y se mencionó principalmente a mujeres como ejemplos negativos para ilustrar falta de adherencia al tratamiento y problemas psicológicos y sociales relacionados con el envejecimiento. Conclusión: Ejemplos de envejecimiento negativo combinados con una invisibilización del género de los pacientes puede guiar hacia el mantenimiento de estereotipos negativos sobre el envejecimiento y la desigualdad de género en la adultez mayor. Se discuten implicaciones para prevenir que esto pase.

Palabras clave. Perspectivas de envejecimiento, envejecimiento active, médicos generales, género, pacientes mayores.

${ }^{1}$ Dr. Catrinel Craciun. Babes-Bolyai University, Romania. Freie Universität Berlin, Faculty of Education and Psychology, Department of Qualitative Social and Educational Research. Germany. Postal Address: Habelschwerdter Allee, 45 14195. Berlin Postal Address: E-mail: craciunic@zedat.fu-berlin.de

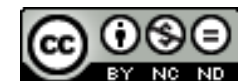

Esta obra está bajo una licencia de Creative Commons Reconocimiento-NoComercial-SinObraDerivada 4.0 Internacional. 


\section{Introduction}

Demographic changes around the Globe increase the need for health professionals to treat aging individuals (Weicht, 2013). Medical treatment and communication imply not only providing accurate medical advice, but also transmitting ideas about positive aging (Craciun \& Flick, 2015) or gender sensitive advice in old age (Reitinger \& Beyer, 2010; Foster \& Walker, 2014). Nevertheless, active aging policy recommendations (Lassen \& Moreira, 2014) might not be easily integrated in busy medical schedules and ideas about active aging that might be accepted in Western contexts may not be popular in Eastern European contexts (Craciun, 2016). Furthermore, older patients may be the target of double stereotyping and discrimination in terms of both age (Levy, 2003) and gender (Palència, 2014). The present article seeks to add to existing literature on aging representations in medical personnel (Liu, Norman, While, 2013; Walter, Flick, Neuber, Fischer, Hussein, Schwartz, 2010) and experiences of general practitioners with older patients (Craciun \& Flick, 2015; Craciun, 2016; Flick, Garms-Homolova, Rönsch, 2012) by exploring how the gender of general practitioners plays a role in their aging representations and how they perceive older women versus older men as patients.

\section{Gender Equality in Health and Aging}

Gender inequalities refer to the differences between women and men that systematically empower one group (usually men) to the disadvantage of the other (usually women).

Gender equality represents an important human right that is achieved when both women and men enjoy the same rights and opportunities (UNDP, 2014). One of these rights is being entitled to live a healthy old age and enjoying quality of life no matter if one is a man or a woman. Nevertheless, this might be more difficult for women as compared to men, even if women are shown to live on average longer lives (Austad, 2006). Economic difficulties that emerge from the fact that women are more likely to be employed in precarious jobs or to be single mothers (Annandale \& Hunt, 2000) may have an influence on their quality of life in old age as compared to that of men. Moreover, older women were shown to act as caregivers for their ill husbands and to suffer negative consequences for their mental and physical health (Schrank et al., 2016). Previous studies reported a gender related disparity in health with either women (Caroli \& Weber-Baghdiguian, 2016) or men (Lipsky, Cannon, Lutfiyya, 2014) at disadvantage concerning health in old age (Bird \& Ricker, 2008). Furthermore, aging itself might be experienced in different ways according to one's gender (Connell, 2012). Gendered access to health care and health problems accumulating over the lifespan might contribute to gender inequalities in old age. In addition, even health care systems themselves, through the ways they are organized, may contribute to emerging and sustaining gender health inequalities (Mackintosh, 2000). Being an older woman might be more difficult than being an older man, and inequality might emerge from the way women and men see their aging as well as how they are seen by others in the society.

\section{Health professionals and aging representations}

Active aging policy means ensuring that older citizens have the right to live a happy, independent old age (Lassen \& Moreira, 2014). It focuses on their healthy lifestyles or on building structures that allow for a positive old age. The present article focuses on the latter in terms of health professionals and their role in healthy aging. General practitioners (GPs) represent the key workers in many health systems. GPs are the ones who have contact with people over the lifetime, and can offer lifestyle advice. GPs views on aging are relevant since they might unknowingly maintain certain negative aging stereotypes by promoting negative images of aging in their work. A positive view of aging means that they see the potential for development and experiencing positive emotions in old age, while negative images of aging mean associating old age with illness and dependency (Levy, 2003; Wurm, Tomasik, \& Tesch-Römer, 2010). Previous studies showed that health professionals had more negative images of aging (Walter et al, 2010; Craciun \& Flick, 2015; Craciun, 2016). The present study wants to go further and explore whether GPs treat men and women differently 
in their practice and whether their representations of older patients are gendered.

Gender may play a role in how GPs relate to aging for several reasons. First, the representation of aging women was shown to be more negative than that of aging men (Smirnova, 2012; Craciun \& Flick, in press). Thus, when interacting with patients, GPs may be affected by the social representation of aging women or men or they might use their own aging representation and project it on their patients. For example, they might be more caring to older women patients because they believe that older women need more help as compared to aging men. Since Romanian men go less to a doctor (Titan \& Otoiu, 2014), the ones that do visit the GP may be more adherent to treatment and could be given as positive examples. Nevertheless, if the GPs are men, they might hold a negative view of their own aging process and use it to evaluate their aging men patients. Present findings should help shed light on this issue.

\section{Aging in Romania}

There older population in Romania is on the rise, with around 15\% of the population being over 65 in 2010 and expected to increase to $30 \%$ by 2050 (Asandului, 2013; Bodogai \& Cutler, 2013). Health inequalities for Romanian pensioners are a reality since their financial situation is below that of other EU countries and economic resources are insufficient for supporting a growing number of older individuals (Bodogai \& Cutler, 2013). Thus, financial independence in old age as active aging policies (Lassen \& Moreira, 2014) envision may be more difficult to reach. Moreover, previous studies have shown that older Romanians (i.e. older than 65) have negative representations of aging (Craciun, 2011), and consider they had few resources to reach a positive old age (Craciun, 2012). Pensions are known to be on average around the equivalent of $225 \$$, representing $50 \%$ of the net average wage, and being far below the living expenses needs (Bodogai \& Cutler, 2013). Since the proportion of older women $(59 \%)$ is higher than that of older men $(41 \%)$, there may be also a higher probability for older women to be at a disadvantage in terms of reaching active aging policy goals.
General practitioners (GPs) may play an important role since older individuals were shown to visit a doctor frequently (Titan \& Otoiu, 2014). For instance, it was shown that as people age, they need more health care services. The proportion of Romanians older than 65 who went to a GP in the last 4 months reached 31.7\% (Titan \& Otoiu, 2014). GPs represent the gate keepers within the Romanian health system, and older individuals cannot benefit from specialist consultations or medicine at reduced price without a recommendation from the general practitioner. In a previous study, it was shown that Romanian doctors have negative views of old age and older persons (Craciun, 2016). This study goes further to investigate whether representations of aging differ between female and male GPs and whether they are treating gender differently concerning aging male and female patients. Gender inequalities might emerge or be strengthened from being treated differently by a GP.

\section{Aims}

The present article explored whether women doctors represent old age differently from men doctors in the context of the Romanian health system. Moreover, it aimed to explore if Romanian general practitioners represent and act in different ways towards male and female older patients.

\section{Methods}

\section{Sample}

A number of 34 interviews were conducted with Romanian general practitioners. The sample comprised 17 women and 17 men, with ages ranging from 30 to 60 years old. Inclusion criteria were (1) having worked or to be working with patients who are older than 65 , (2) medical practice experience of at least three years and (3) to be working in a public clinic or private practice. Snowballing technique was used for participants' recruitment. All participants were informed about the study aims and signed consent forms regarding their participation. Confidentiality and anonymity were guaranteed to all study participants. Ethical aspects of the study were approved by the ethical board of the Babes Bolyai University in Cluj Napoca. 


\section{Data Collection}

Episodic interviews (Flick, 2014) were carried out in order to collect data. The basic assumption for episodic interviews is that people encode and retrieve information in form of semantic and episodic knowledge. Semantic knowledge refers to concepts and relations between these, as for instance the concept of old age and its relation to health. Episodic knowledge describes the context where we have learned the semantic contexts are learned. For instance, in the case of the present study this would be the medical everyday context where GPs meet their patients and offer medical advice. The interview guide comprised nine questions including topics such as what is the GPs experience with older adults as patients, how they would describe an older patient as compared to younger ones, how they perceive aging ("what does aging mean to you?"), how they perceive female versus male patients. Interviews took around 40 minutes to complete and were carried out at the hospitals or medical practices where the GPs worked. All interviews were transcribed verbatim for the purpose of analysis.

\section{Data Analysis}

Data analysis was performed with thematic coding (Flick, 2014). This method was chosen as it was proven effective in case of comparative studies where the groups under study have already been defined within the research question (Flick, 2014; Flick et al, 2012). The underlying assumption is that differing views can be found in different social groups concerning the same topic that makes the subject of research. Patterns of interpretations and practice were identified within the statements of the professionals. All interviews were first analyzed as a series of case studies (i.e. all interviews) and all statements were coded for thematic areas (e.g. Representations of aging) and for each case (each single interview). In a second step of the analysis, comparative dimensions were identified for each case. They were used as a starting point to identify common aspects and differences between interviews. Based on these dimensions and their features the cases were classified and analyzed for specific combinations of features. For instance, the analysis focused on how female and male GPs represented aging and how they performed gender in their practice of treating older women and men. Similarities and differences between female and male GPs were identified in order to identify typologies of patterns of interpretations and practices which were then analyzed in terms of their contexts of meaning following the model of previous research (Craciun \& Flick, 2015). The identified themes were checked for reliability by two other research assistants. The author conducted the analysis in Romanian with the use of Atlas.ti software and translated selected quotes into English for the purpose of this article.

\section{Results}

\section{(De)Gendered representations of aging among GPs}

Both female and male GPs represented old age as being something negative. For instance, old age was associated with illness, loneliness and dependency.

Old age is when you start depending on others, you start forgetting things, you cannot take care of yourself anymore, you forget your medicine, you have no appetite, and you start thinking about death and the life you had before (GP07, f, 38 years old).

The relevance of subjective age was emphasized, especially the difference between chronological age and actual age. However, this was done pointing that one could already be ill and dependent in ones' fifties and not necessary only in ones' seventies, not that one could still be healthy and happy in ones' eighties.

I believe you are old when your body is old, the illness is so bad that it cannot fight anymore and no medicine can help, not the age in years is relevant (GO06, f, 57 years old).

When talking about ways in which to reach a good old age, women GPs accentuated psychological aspects such as being "at peace with yourself", getting rid of negative emotions, the importance of socialization and having a positive attitude towards young people. Among the interviewed GPs, men mentioned an active lifestyle or a positive state of mind as ways in which one could reach old age. The greatest barriers for aging well were considered to be the economic situation and 
the state of the health care system, as described by all interviewed GPs regardless of their gender.

\section{(De) Gendered Representations and Actions towards olderpatients}

In what concerns how general practitioners perceived their older patients, no differences emerged among the interviewed women and men GPs. The common theme was that of the difficult patient, regardless of the patients' gender. Cases of women patients were chosen to illustrate negative aspects related to the aging population such as their vulnerability and dependence.

\section{The "difficult" patient}

Both older women and men were described as being "difficult" patients. Being difficult, meant that for instance, an older patient would not understand medical advice. Moreover, even if patients understood the medical terminology, they would not comply with medical recommendations. The interviewed GPs believed that making lifestyle changes in one's old age was very difficult since they believed older people are not open to change and learn new things with difficulty, as one participant pointed out:

In case of patients who are older than $65 \mathrm{I}$ have to repeat the medical information several times, how to take the medicine for instance...they usually always say yes and nod as if they had understood but in the end I have to talk to their children to make sure they do what I advised (GP06, m, 36).

In addition to not being able to grasp what the doctors recommend, difficult patients were also described as being rude and uncooperative, and even sometimes threatening as another participant mentioned:

I am bothered by the ones who don't pay attention and are rude, they use bad language, they display a superiority attitude, they threaten they will complain to the authorities. I just ignore them, there is no use talking to them. After all these work experience, I know I do not need to bother too much with them. They have their own worries and will not understand what I want to tell them (GP03, f, 46).

Despite the negative depiction of the older patients' behavior, the GP in the example above displayed an understanding attitude towards the difficulties that older patients face in their daily lived lives, and that may make them seem unfriendly in the medical context where they are stressed.

Difficult patients were also described as older individuals who are not adherent to treatment because they forget to take medicine as a "normal" characteristic of old age. Since they did not understand the treatment program and effects, old people were considered "irresponsible" or were described as depending on other adults to take care of them and bring them to the GP when medical symptoms occur:

For instance this old lady, she takes her medicine a few days, than she sees she does not feel good, than she stops taking her medicine. Than when she gets sick, a neighbor brings her to me. I tell her that she needs to take the medicine the whole long period for it to have an effect, but she does not want to understand. She says it doesn't matter anymore, she does not want to live, to be a burden for others (GP02, f, 40).

In the example above, the "difficult" behavior of the patient emerged from the difficulties of old age itself. Older people were reluctant to medical advice since they felt they hadve lived enough and did not want to invest effort into getting better. There was no mention of gender differences in how a GP should treat or communicate with older patients or about tailoring advice to men and women's' needs. Physical aspects seemed to matter more when GPs spoke about female patients; however, it could also be that older women visit a doctor more frequently than older men do. For instance, one male GP said old age can be recognized by physical signs that were more important than chronological age itself when estimating a persons' age:

The other day two women came to my practice, I was surprised to find out that the one with wrinkles and bags under her eyes was the daughter of the other one whose appearance did not show her age. Stress, lack of sleep and smoking made the daughter look older (GP10, m, 54).

Men were given as positive examples when GPs talked about older patients who were adherent to 
treatment despite difficulties. For instance, one GP recounted a story about an older patient who used to drink and smoke a lot, but after receiving the news that he has diabetes, he started following the treatment and the lifestyle changes:

I have never seen something like this before. That at his age he could still become adherent to treatment, but these cases are rare, one in a million.(GP02, $\mathrm{f}, 40$ years old).

Women patients were often presented as negative examples for treatment non-adherence. For instance, one GP talked about a case where an older woman did not understand the medical advice:

She just said yes to everything I told her, but she did not understand, in the end she did not know what she needed to do, so I had to talk to other child and explain all to him again how his mother should take the medicine (GP07, f, 38 years old).

Older women were also depicted as having psychological problems such as depression or feelings of resentment that interfered with their aging well:

I had this patient, this 75 year old woman, she was ill and she had difficulties relating with others. She did not get along with her daughter, she felt she was not appreciated for her sacrifices, the efforts she invested for her grandsons, and she could not forgive her daughter for marrying without telling her, she had a shock and just aged sooner (GP09, m, 37 years old).

All in all, GPs referred to older patients as a homogenous group, characterized by illness, poverty and loneliness. Poverty was presented as the consequence of small pensions and high living expenses, high costs of medicine included.

Loneliness was seen as the effect of families not living together anymore, for instance children and grandchildren living far from the older family members, mostly in other countries. Women were given as an example to illustrate how sometimes older patients become social cases that need help more than in the medical domain.

For instance, one GP recounted how he helped one woman female patient find a job :
I usually have patients who are looking for a job. This older lady came to me and asked if I could recommend her to somebody that needed help with their children because she is good with children and could do such work. So I recommended her to a family and now she has been working for 10 years by this family, she has become part of the family herself almost (GP15, m, 58 years old).

The above example may also be regarded as a success story where an older woman found "a new" family and meaning in old age.

\section{Discussion}

Images of aging and gender might placeut either older women or older men at a disadvantage and increase gender inequalities in old age. Present findings lend support to previous literature showing that medical personnel tends to have rather negative images of old age (Walter et al., 2010; Craciun \& Flick, 2015; Craciun, 2016). Having a negative image of aging may reflect on how they treat older patients and contribute to the maintenance of negative stereotypes related to old age (Craciun, 2016). Furthermore, even if the GPs tried to promote a positive old age in their practice, their own negative images of old age might constitute a relevant barrier in this endeavor (Craciun \& Flick, 2015). The association between old age and illness might be particularly dangerous in case of medical personnel. On the one hand, previous research has shown that in order to have a positive view of aging one should dissociate old age from illness (Wurm et al. 2010). On the other hand, previous findings showed negative images of aging become self-fulfilling prophecies (Wurm, Warner, Ziegelmann, Wolff, Schüz, 2013). Thus, if medical doctors hold negative images of aging, they are at risk themselves for lower longevity and lower quality of life in old age (Levy, 2003). Furthermore, they may transmit the negative image of aging to their patients or develop a negative attitude towards elderly patients based on such negative aging views. Nevertheless, the image of the "difficult patient" may be also interpreted as a realistic view of the difficulties faced by older patients in their daily lives. Although it may reflect a negative view of old 
age, it does not automatically translate into a negative attitude towards older people and patients in particular. On the contrary, some GPs displayed an emphatic attitude by showing that they understand the difficult circumstances of their older patients. In practice, GPs should help their patients interpret symptoms as caused by certain medical problems like diabetes or high blood pressure and not by old age itself and help them deal with those symptoms by taking medicine or making lifestyle changes. All in all, findings pointed out that both male and female GPs displayed a negative representation of old age, although in the existing literature women seem more prone to have a negative representation of old age (Smirnova, 2012; Craciun \& Flick, in press).

In what concerned the second research question, findings showed that GPs saw both older women and men as vulnerable patients. The fact that older women were given as examples to illustrate the bad condition of the "Romanian old person" could mean that there are more negative representations of ill or needy older women and these representations were therefore easier accessed and activated. It may also mean that "being dependent" and "weak" were seen as rather feminine traits and that older men were also invested with these feminine qualities and treated as part of the same group of "difficult" older patients. Nevertheless, it could also be that more examples of women are provided since Romanian women are known to visit doctors more often as compared to men (Titan \& Otoiu, 2014).

The fact that no particular gender differences emerged in how GPs perceive older patients may also be interpreted as suggested by another study, that a degendering of older people (Silver, 2003), in this case older patients, takes place. Treating older patients as a homogeneous, a "degendered" group, does not automatically mean that older women and men are treated equally in terms of their rights to good health care and information about positive aging. It may mean that gender issues are not considered that relevant or are not addressed specifically in the medical context since health is human right, not depending on gender. However, the fact that older patients get treated like a homogeneous group leaves space for negative aging stereotyping to strive (Levy, 2003). Focusing on negative examples, may make the negative age stereotype stronger. Moreover, for some of the interviewed GPs even if the age difference with the patients they talk about is not that big (i.e. between 5 and 15 years), they described the older patients as belonging to a totally different age group with limited opportunities for growing old in an active or dignified way. This could mean that the interviewees attempted to distance themselves from the patients they were dealing with, not acknowledging the fact that they could someday become aging patients themselves.

Present findings should be expanded with quantitative studies on how negative versus positive representations of aging in GPs influence their actions in practice and the views on aging of their patients. Furthermore, the views of health professionals and patients alike are relevant. For example, even if the views of GPs go into the direction of active aging and gender equality, there might be differences in what concerns how their aging patients understand these issues. Thus, the views of the patients may be explored in a future study and contrasted with the views of the GPs on topics such as aging, health and gender. The present study represents a first step in the direction of showing why some active aging policy principles as well as gender equality issues could be still difficult to implement in the Romanian health system and how gender inequalities might be sustained involuntarily. Future studies should also look at how interventions may be developed and tested for effectiveness in what concerns changing negative views of aging among GPs and helping them adopt more gender sensitive health communication with their older patients.

The first step towards effective interventions would be that GPs would believe in a positive old age, and second they would implement active aging ideas in their work. As pointed out in a previous study, GPs should increase their self-efficacy towards implementing active aging policy (Craciun, 2016). Moreover, GPs should be sensitive to gender differences (Foster \& Walker, 2014) and adapt their discourse and treatment advice to the 
needs of older women and men. Sense of control was shown to be important for life satisfaction in old age (Wiest, Schüz, Wurm, 2012) and GPs might try to develop this for their older patients in order to improve the quality of life. As an important implication for practice, health communication workshops for GPs should be organized to address issues such as acknowledging gender differences between aging women and men, but deceasing gender inequality among older patients. This may represent a step forward towards tackle health inequalities as well as gender inequalities among Romanian pensioners in particular, but also between countries in what concerns implementing active aging policies (Lassen \& Moreira, 2014) and gender equality policies (Palència et al., 2014).

\section{References}

Annandale, E. \& Hunt, K. (2000). Gender Inequalities in Health. Buckingham: Open University Press.

Asandului, L. (2013). Population Aging in Romania: Facts and Analysis. Retrieved from http://msed.vse.cz/ files/2012/Asandului_2012.pdf

Austad, S. N. (2006). Why women live longer than men: Sex differences in longevity. Gender Medicine, 3(2), 79-92. doi:10.1016/s1550-8579(06)80198-1

Bird, C. E., \& Rieker, P. P. (2008). Gender and Health. New York: Cambridge University Press. doi:10.1017/ cbo9780511807305

Bodogai, S. I., \& Cutler, S. J. (2013). Aging in Romania: Research and Public Policy. The Gerontologist, 54(2), 147-152. doi:10.1093/geront/gnt080

Caroli, E., \& Weber-Baghdiguian, L. (2016). Selfreported health and gender: The role of social norms. Social Science \& Medicine, 153, 220-229. doi:10.1016/j.socscimed.2016.02.023

Connell, R. (2012). Gender, health and theory: Conceptualizing the issue, in local and world perspective. Social Science \& Medicine, 74(11), 16751683. doi:10.1016/j.socscimed.2011.06.006

Craciun, C. (2016). "They Do Not Know How To Use Their Health Insurance Card": Implementation of Active Aging Policy and Aging Perceptions in Romanian General Practitioners. Ageing International, 41. doi:10.1007/s12126-015-9239-x

Craciun, C. \& Flick, U. (2015). I wonder if robots will take care of me when I am old: Positive aging representations of professionals working in health promotion services. Journal of Health Psychology. doi:10.1177/1359105315587141

Craciun, C. (2011). Successful Aging-Utopia or the Result of Lifelong Learning? Meaning and Representations of Ageing in Romanian Elderly. Ageing International, 37(4), 373-385. doi:10.1007/s12126-011-9131-2

Craciun, C. (2012). Social Capital in Romanian Old People: Meanings and Opportunities for Health. Ageing International, 39(2), 106-123. doi:10.1007/ s12126-012-9157-0

Craciun, C. \& Flick, U. (in press) Aging in precarious times: exploring the role of gender in shaping views on aging, Journal of Women \& Aging.

Flick, U. Garms-Homolová, V., Röhnsch, G. (2012). "And mostly they have a need for sleeping pills": Physicians' views on treatment of sleep disorders with drugs in nursing homes. Journal of Aging Studies, 26, 484-494.

Flick, U. (2014). An Introduction to Qualitative Research - Fifth edition. London/ Thou-sand Oaks, CA/ Dehli: Sage.

Foster, L., \& Walker, A. (2014). Active and Successful Aging: A European Policy Perspective. The Gerontologist, 55(1), 83-90. doi:10.1093/geront/gnu028

Lassen, A. J., \& Moreira, T. (2014). Unmaking old age: Political and cognitive formats of active ageing. Journal of Aging Studies, 30, 33-46. doi:10.1016/j. jaging.2014.03.004

Mackintosh, M. (2000). Do health care systems contribute to inequality? In: Leon, David and Walt, Gill (eds). Poverty, Inequality and Health: An International Perspective. Oxford: Oxford University Press, pp. 175-193. doi:10.1093/acprof:o so/9780192631961.003.0009 
Levy, B. R. (2003). Mind matters: Cognitive and physical effects of aging self-stereotypes. The Journals of Gerontology, Series B: Psychological Sciences and Social Sciences, 58, P203-P211. doi:10.1093/ geronb/58.4.P203

Lipsky, M. S., Cannon, M., \& Lutfiyya, M. N. (2014). Gender and health disparities: The case of male gender. Disease-a-Month, 60(4), 138-144. doi:10.1016/j.disamonth.2014.02.001

Liu, Y., Norman, I. J., \& While, A. E. (2013). Nurses' attitudes towards older people: A systematic review. International Journal of Nursing Studies, 50(9), 12711282. doi:10.1016/j.ijnurstu.2012.11.021

Palència, L., Malmusi, D., De Moortel, D., Artazcoz, L., Backhans, M., Vanroelen, C., \& Borrell, C. (2014). The influence of gender equality policies on gender inequalities in health in Europe. Social Science \& Medicine, 117, 25-33. doi:10.1016/j.socscimed.2014.07.018

Schrank, B., Ebert-Vogel, A., Amering, M., Masel, E. K., Neubauer, M., Watzke, H., ... Schur, S. (2015). Gender differences in caregiver burden and its determinants in family members of terminally ill cancer patients. Psycho-Oncology, 25(7), 808-814. doi:10.1002/pon.4005

Silver, C. B. (2003). Gendered identities in old age: Toward (de)gendering? Journal of Aging Studies, 17(4), 379-397. doi:10.1016/s0890-4065(03)00059-8

Smirnova, M. H. (2012). A will to youth: The woman's anti-aging elixir. Social Science \& Medicine, 75(7), 1236 1243. doi:10.1016/j.socscimed.2012.02.061

Titan, E., \& Otoiu, A. (2014). Does Aging Influence Migration in Romania? A Comprehensive Analysis.
Procedia Economics and Finance, 10, 87-96. doi:10.1016/ s2212-5671(14)00281-0

Walter, U., Flick, U., Neuber, A., Fischer, C., Hussein, R. J., \& Schwartz, F. W. (2010). Putting prevention into practice: qualitative study of factors that inhibit and promote preventive care by general practitioners, with a focus on elderly patients. BMC Family Practice, 11(1), 68. doi:10.1186/1471-2296-11-68

Weicht, B. (2013). The making of "the elderly": Constructing the subject of care. Journal of Aging Studies, 27(2), 188-197. doi:10.1016/j. jaging.2013.03.001

Wiest, M., Schuz, B., \& Wurm, S. (2012). Life satisfaction and feeling in control: Indicators of successful aging predict mortality in old age. Journal of Health Psychology, 18(9), 1199-1208. doi:10.1177/1359105312459099

Wurm, S., Tomasik, M. J., \& Tesch-Römer, C. (2010). On the importance of a positive view on ageing for physical exercise among middle-aged and older adults: Cross-sectional and longitudinal findings. Psychology \& Health, 25(1), 25-42. doi:10.1080/08870440802311314

Wurm, S., Warner, L. M., Ziegelmann, J. P., Wolff, J. K., $\&$ Schüz, B. (2013). How do negative self-perceptions of aging become a self-fulfilling prophecy? Psychology and Aging, 28(4), 1088-1097. doi:10.1037/a0032845

UNDP, United Nations Development Program (2014). Gender Equality Strategy 2014-2017. New York: USA. 
